\title{
Establishment of a Hub for the Light Water Reactor Sustainability Online Monitoring Community
}

Nancy J. Lybeck Magdy S. Tawfik Binh T. Pham

August 2011

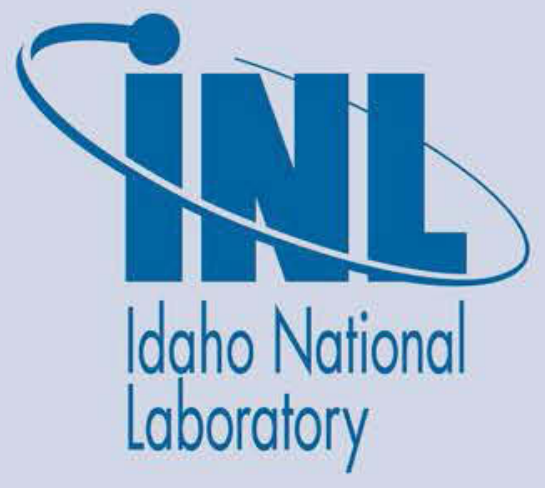

The INL is a U.S. Department of Energy National Laboratory operated by Battelle Energy Alliance 


\section{DISCLAIMER}

This information was prepared as an account of work sponsored by an agency of the U.S. Government. Neither the U.S. Government nor any agency thereof, nor any of their employees, makes any warranty, expressed or implied, or assumes any legal liability or responsibility for the accuracy, completeness, or usefulness, of any information, apparatus, product, or process disclosed, or represents that its use would not infringe privately owned rights. References herein to any specific commercial product, process, or service by trade name, trade mark, manufacturer, or otherwise, does not necessarily constitute or imply its endorsement, recommendation, or favoring by the U.S. Government or any agency thereof. The views and opinions of authors expressed herein do not necessarily state or reflect those of the U.S. Government or any agency thereof. 


\title{
Establishment of a Hub for the Light Water Reactor Sustainability Online Monitoring Community
}

\author{
Nancy J. Lybeck \\ Magdy S. Tawfik \\ Binh T. Pham
}

August 2011

Idaho National Laboratory Idaho Falls, Idaho 83415

http://www.inl.gov

Prepared under Work Package L-11N060201

Prepared for the

U.S. Department of Energy

Office of Nuclear Energy

Under DOE Idaho Operations Office

Contract DE-AC07-05ID14517 



\section{ABSTRACT}

Implementation of online monitoring (OLM) and prognostics in existing U.S. nuclear power plants will involve coordinating the efforts of national laboratories, utilities, universities, and private companies. Internet-based collaborative work environments provide necessary communication tools to facilitate interaction between geographically diverse participants. Available technologies were considered, and a collaborative workspace was established at INL as a hub for the light water reactor sustainability OLM community. 


\section{CONTENTS}

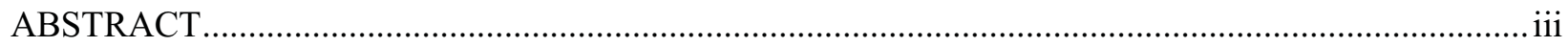

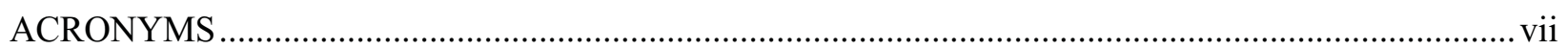

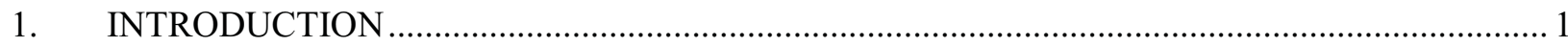

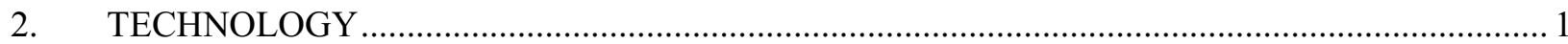

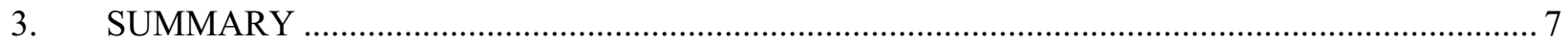

\section{FIGURES}

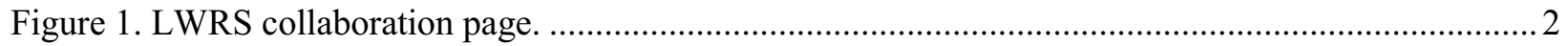

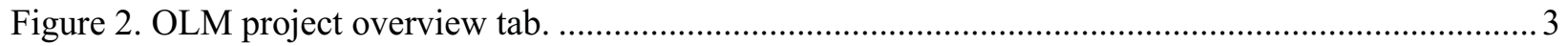

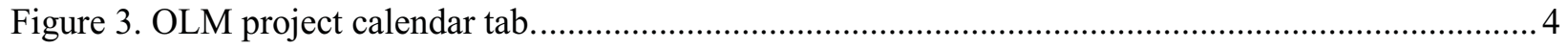

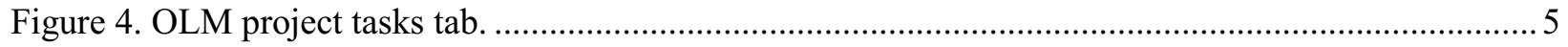

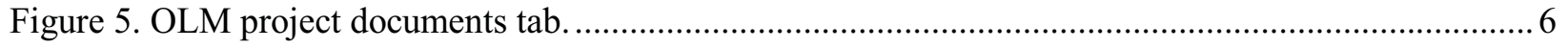

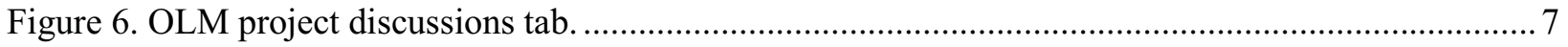




\section{ACRONYMS}

EPRI Electric Power Research Institute

HTTPS Hypertext Transfer Protocol Secure

INL Idaho National Laboratory

LWRS Light Water Reactor Sustainability

NEUP Nuclear Energy University Programs

NPP Nuclear Power Plants

OLM OLM

ORNL Oak Ridge National Laboratory

PNNL Pacific Northwest National Laboratory 


\section{Establishment of a Hub for the Light Water Reactor Sustainability Online Monitoring Community}

\section{INTRODUCTION}

The implementation of OLM and prognostics in existing U.S. nuclear power plants (NPPs) is the ultimate goal of the OLM pathway. Successful completion of this goal will involve cooperation between many stakeholders, including Idaho National Laboratory (INL), Pacific Northwest National Laboratory (PNNL), Oak Ridge National Laboratory (ORNL), universities participating in the Nuclear Energy University Programs (NEUP), the Electric Power Research Institute (EPRI), utilities, etc. The use of communication tools will be critical for the success of this project. Because the participants are geographically scattered, the use of an Internet-based collaborative work environment was the focus of this research.

There are many collaboration tools available for use, ranging from free applications like Google Docs to enterprise applications like Microsoft SharePoint and Team Foundation Server. These systems offer a variety of capabilities (e.g., e-mail, calendaring, chatting, and file sharing). For this project, the desired capabilities include document sharing and collaborative editing, group calendar, discussions, and task management. Security requirements include the ability to control access to the data, secure data transmission, and the ability to upload encrypted files.

Based on cost, availability, and features, the INL portal technology was selected. The hub was established as a new project under the existing Light Water Reactor Sustainability (LWRS) portal (https://inlportal.inl.gov). Access to the project is restricted to named users approved based on the need to know as well as individual security plans. Currently, 13 user accounts have been established, including participants from INL, PNNL, ORNL, EPRI, University of Tennessee, and The Ohio State University.

\section{TECHNOLOGY}

The INL portal is based on Web Center Interaction, an Oracle product. Communities of users are established with common interests (e.g., the LWRS community). Projects are established within each community to organize material as well as control access. Using role-based security, each individual user will see only the projects to which he/she is granted access. Currently, one project has been established under the LWRS community for the OLM community. Additional projects will be added as necessary.

The INL portal has all the required capabilities for the hub: document sharing and collaborative editing, group calendar, discussions, and task management. All portal files are backed up nightly, and Hypertext Transfer Protocol Secure (HTTPS) encryption is used for secure data transmission. The help capabilities include videos with brief introductions to teach users how to use the system to accomplish specific tasks (spotlights). Using a subscription service, this system can send users notification via e-mail when documents are updated, announcements are posted by the project leader, and items are added to the calendar or task list. Users can also use the system to send e-mail notification of activities to other project members.

The LWRS collaboration page shows users recent information from the common LWRS community and from the specific projects to which he/she is assigned (Figure 1). The project links open in a new window. The standard layout for each project window has five tabs: overview, calendar, tasks, documents, and discussions. Figure 2 through Figure 6 shows screenshots for the OLM project tabs. 


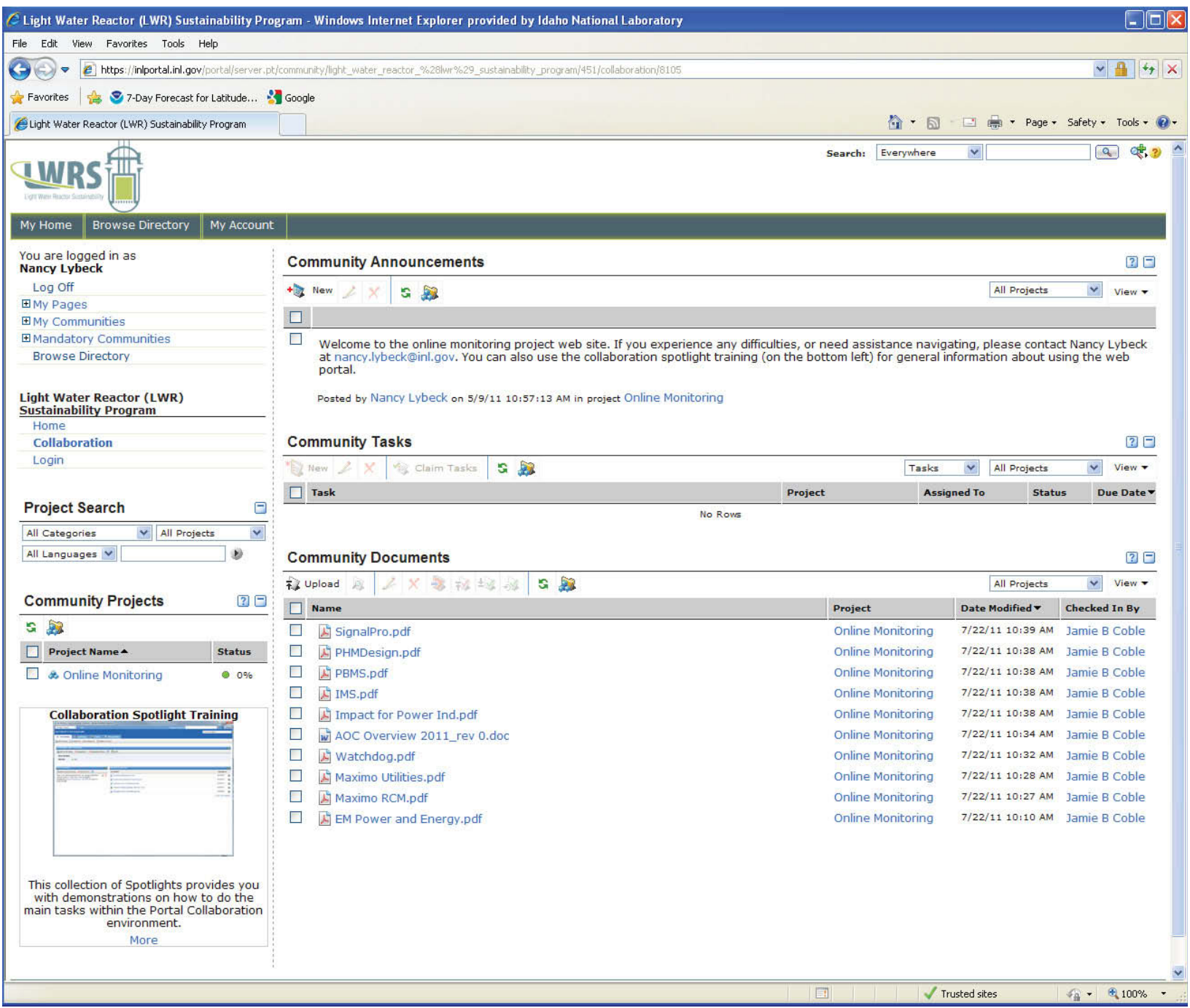

Figure 1. LWRS collaboration page. 


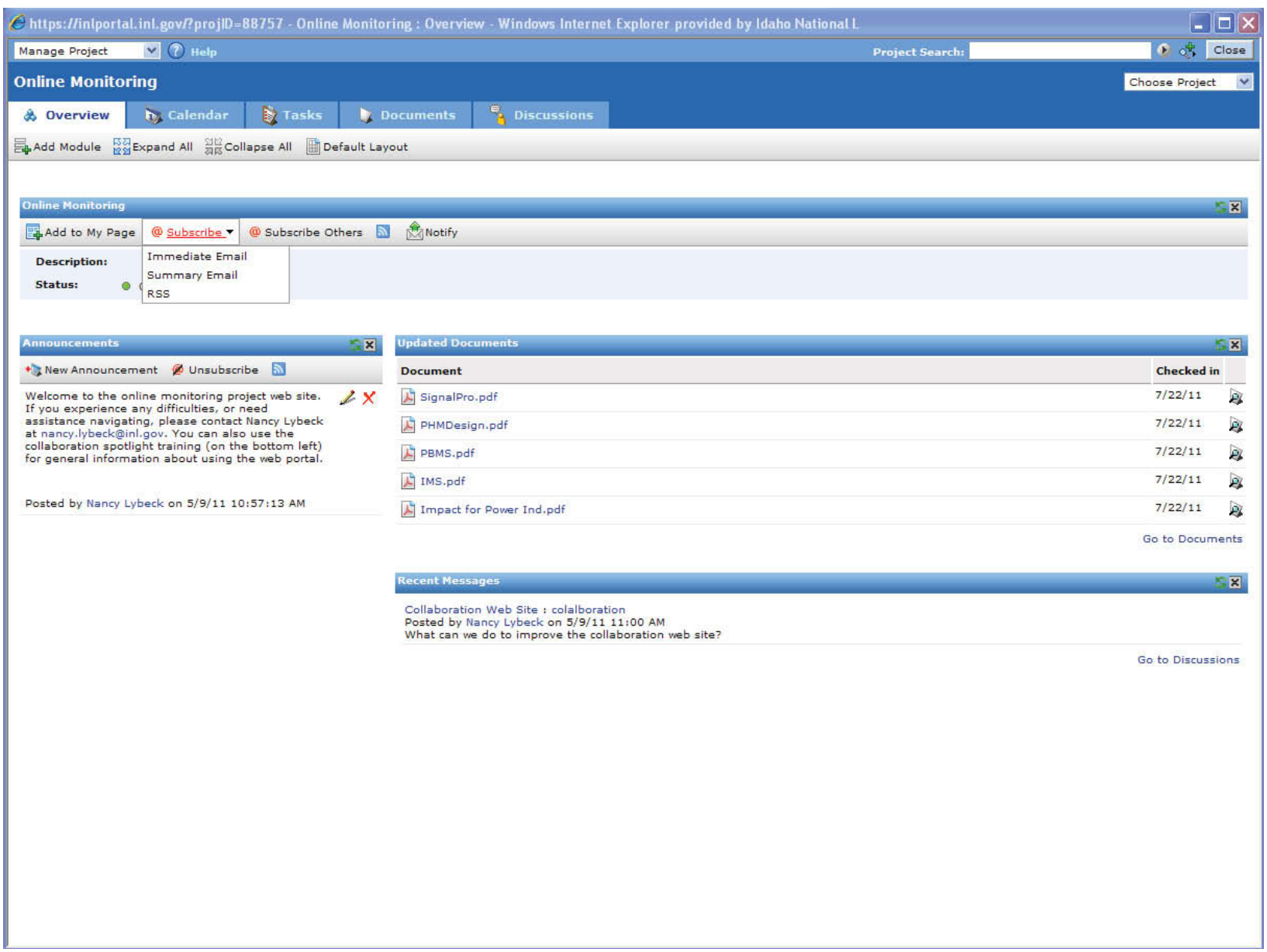

Figure 2. OLM project overview tab. 


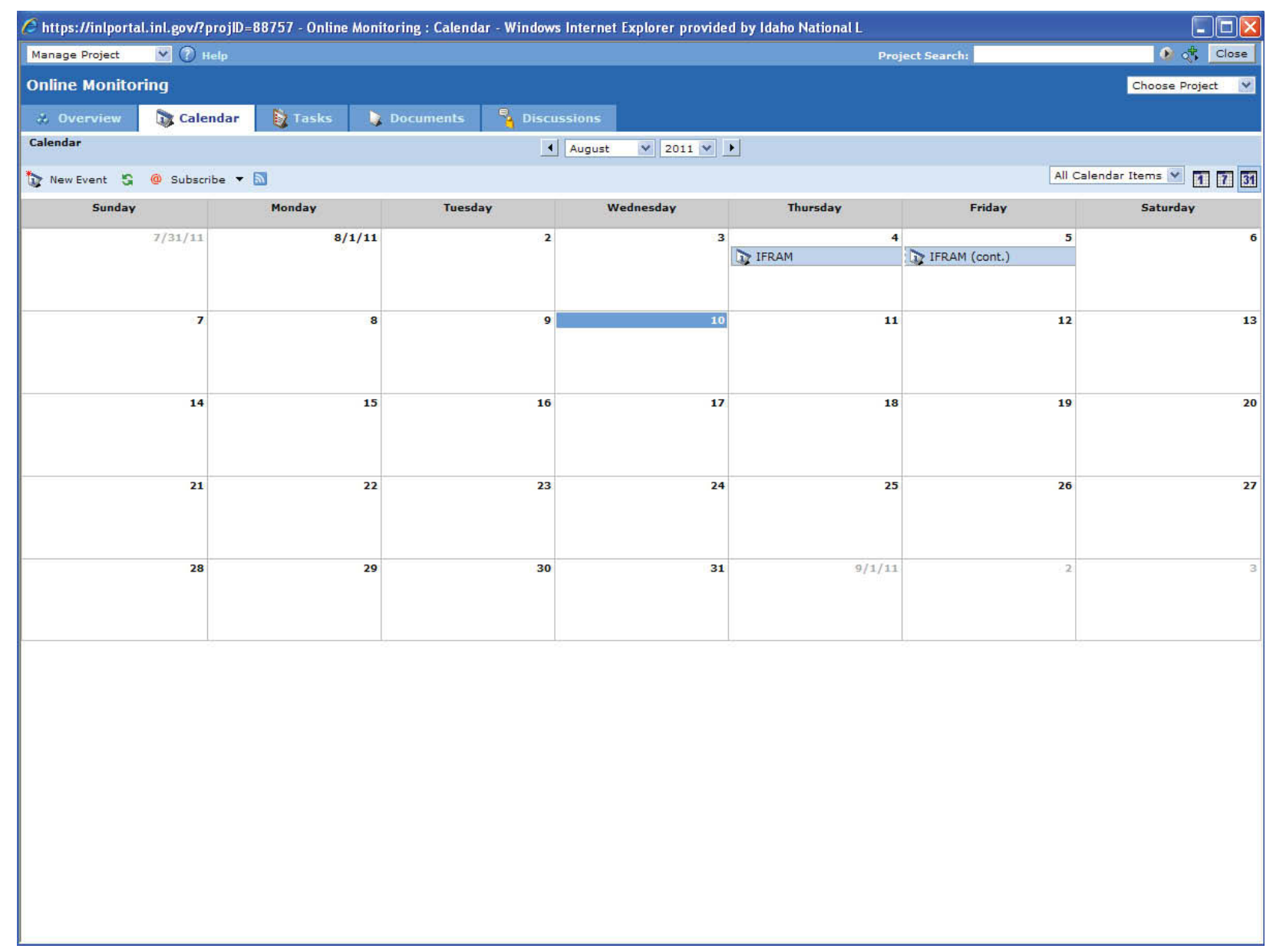

Figure 3. OLM project calendar tab. 


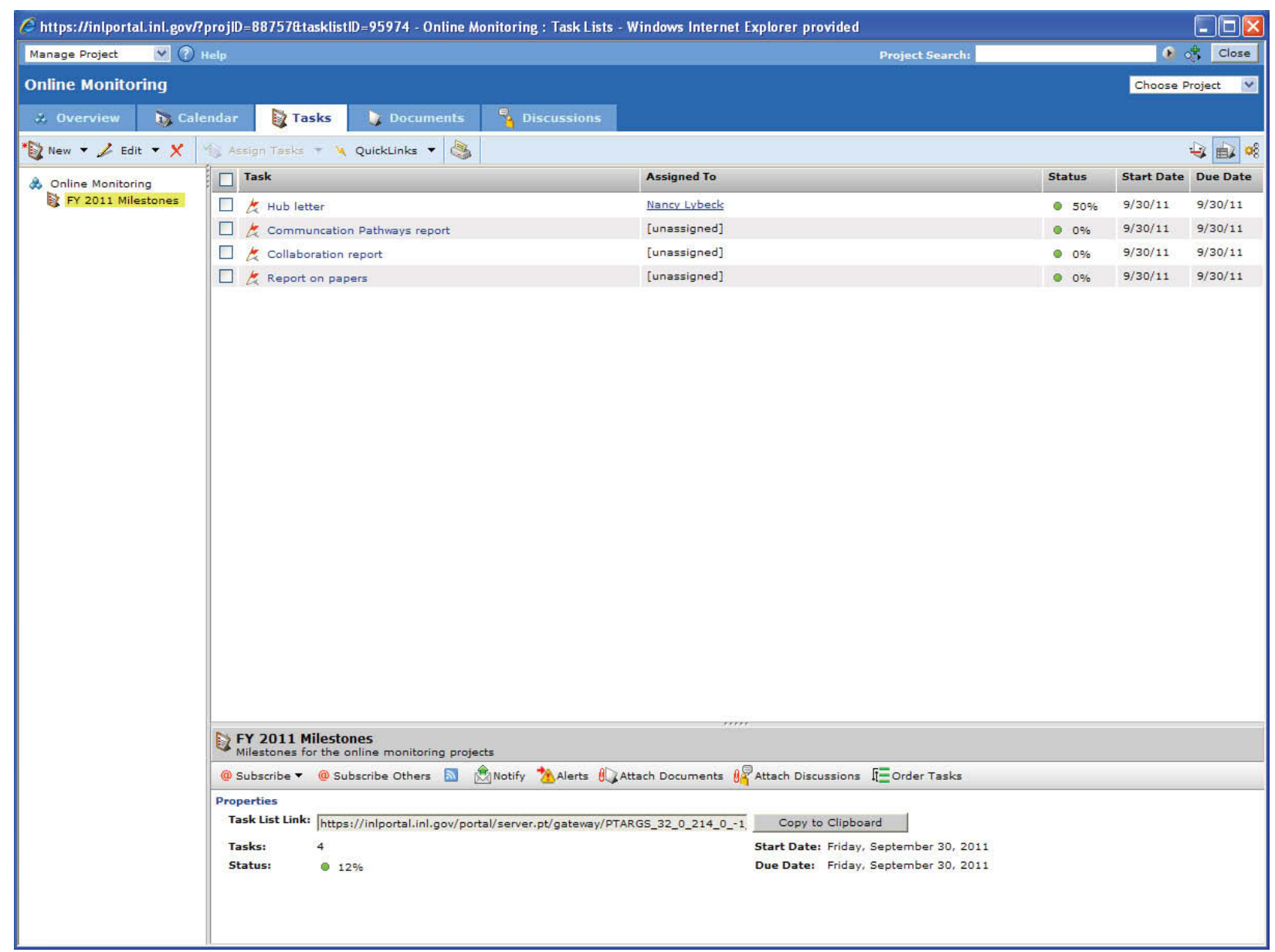

Figure 4. OLM project tasks tab. 


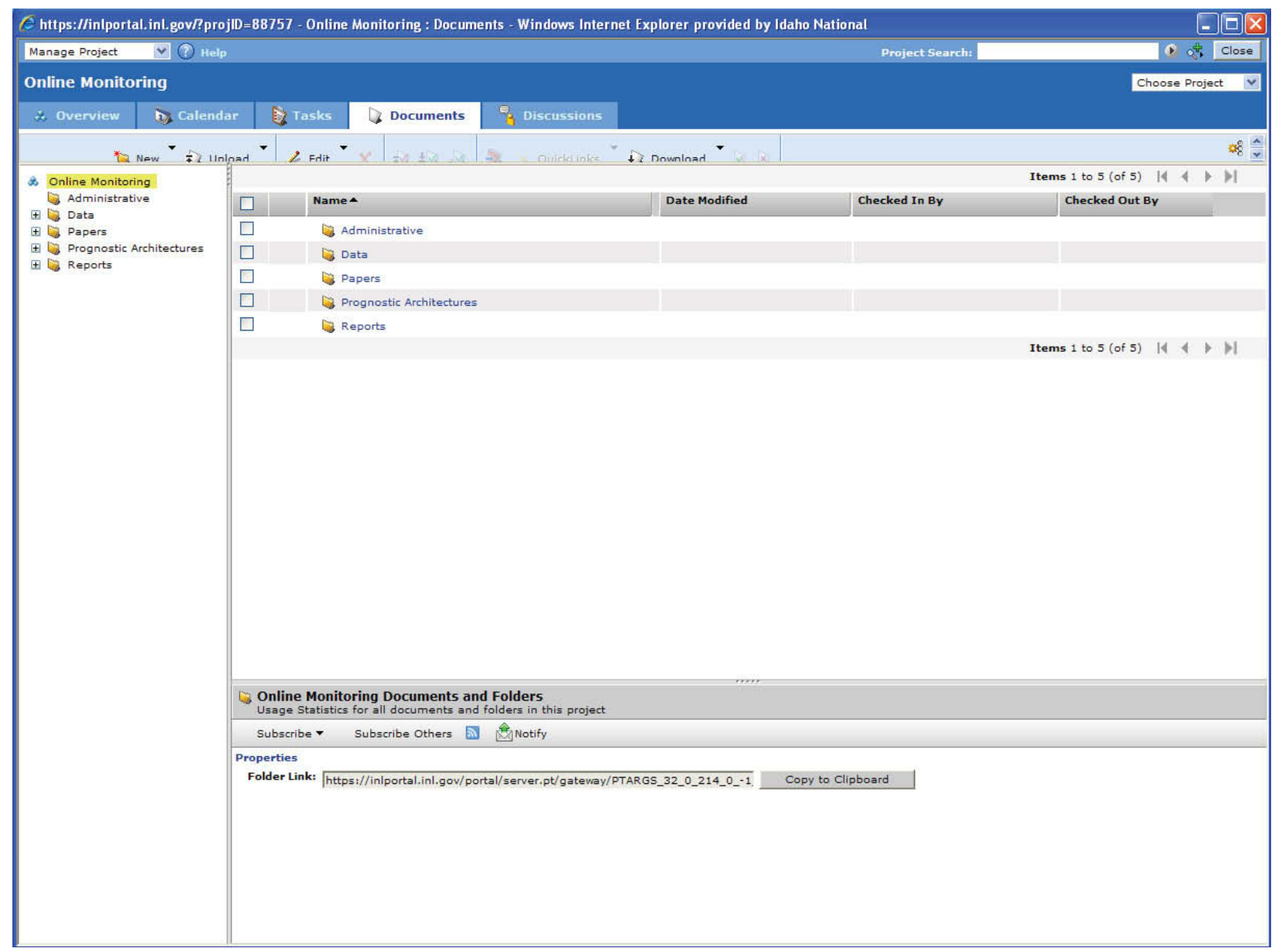

Figure 5. OLM project documents tab. 


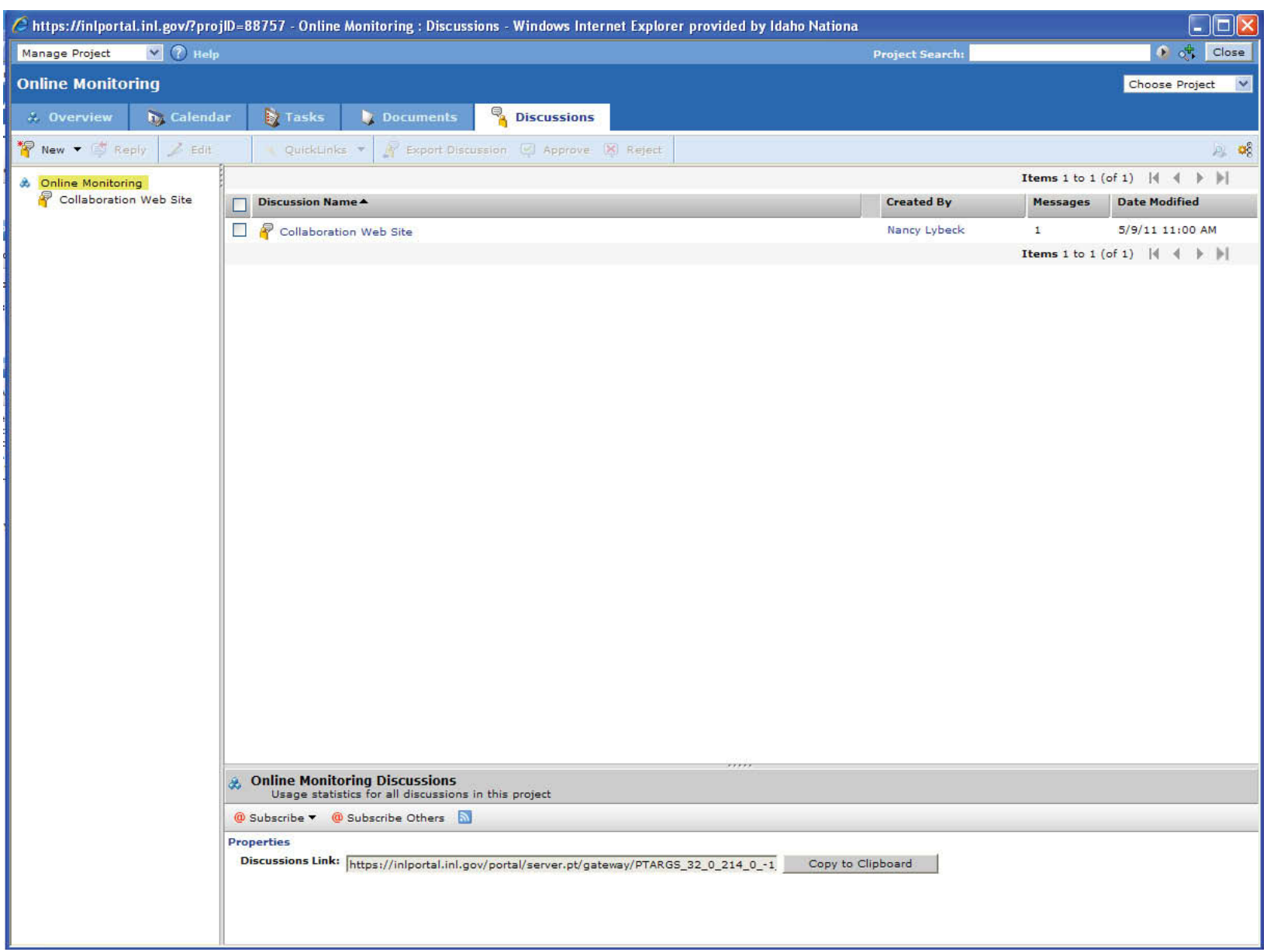

Figure 6. OLM project discussions tab.

\section{SUMMARY}

A collaborative workspace was established at INL as a hub for OLM, which is a powerful tool that provides the means to safely and securely distribute information, manage tasks, write joint documents, and initiate discussions within the community. It can be accessed from virtually any computer environment, which easily accommodating traveling project members. The hub is expected to be a valuable asset as deployment of OLM moves forward in existing U.S. NPPs. Individuals desiring to use the hub may follow the instructions on the portal login page (https://inlportal.inl.gov) to request access to the OLM project under the LWRS community. 